changes were present in the shoulder, hip, and knee joints, characterised by narrowing of the joint spaces and irregularities of the articulate surfaces. There were milder but similar changes in the ankle. The upper extremities were shorter than the lower extremities. The hands and feet were entirely normal.

\section{Discussion}

The characteristically progressive radiological findings affecting the spine and epiphyses seen in SEDT are not, in themselves, diagnostic of SEDT but are found in several of the skeletal dysplasias, ${ }^{+}$and SEDT is a heterogeneous group of disorders both in clinical presentation and in genetic transmission. ${ }^{45} \mathrm{~A}$ subclassification is important in order to be able to give more specific and precise genetic counselling. Inheritance of SEDT is usually $\mathrm{X}$ linked recessive, but some cases of autosomal recessive and autosomal dominant inheritance are known. Occasionally, the clinical history and family pedigree can help in making a definitive diagnosis. More often, however, when confronted with a sporadic case and a negative family history, a specific diagnosis cannot be made. The dilemma occurs when genetic counselling is required. It would be of importance to the clinician if specific variants and their inheritance could be identified.

The clinical history and $x$ ray findings in the three patients presented here establish the diagnosis of
SEDT. ${ }^{2}$ Previous reports have indicated normal mentality in SEDT. The family described here, with three affected mentally retarded daughters born to healthy, related parents, and the history of similarly affected mentally retarded first cousins also born to consanguineous parents, where all other children in the kindred are mentally normal, is most compatible with a new variant of SEDT with autosomal recessive inheritance.

The delineation of this new variant of SEDT should prove useful in the counselling of sporadic cases of SEDT. Description of new cases is important for more precise classification of variants of SEDT in the future and is essential for counselling of cases that are thought to be sporadic.

\section{References \\ 1 Rubin P. Dvnamic classification of bone dysplasia. (hicago: Year Book Medical Publishers. 1964:105-20. \\ - Silverman FN. Spondylocpiphyseal dysplasia tarda. Semin Roentgenol 1973:8:229. \\ ${ }^{3}$ Langer LO Jr. Spondyloepiphyseal dysplasia tarda. Hereditary chondrodysplasia with characteristic vertebral configuration in the adult. Radiology 1964:82:833-9. \\ + Spranger J. Langer LO. Spondylo-epiphyscal dysplasias. Birth Defects 1974:1(9):19-61. \\ " Connor JM. Evans DAP. Sardharwalla IB. An adult femalc with spondyloepiphyseal dysplasia tarda. J Med Genet 1982:19: 234-6.}

Correspondence and requests for reprints to $\mathrm{Dr}$ Gertrude Kohn, Division of Medical Genetics, Beilinson Medical Center, Petah-Tikva, Israel.

\title{
Hypoplastic tibiae with postaxial polysyndactyly: a new dominant syndrome?
}

\author{
S A AL-AWADI, K K NAGUIB, T I FARAG, AND A S TEEBI \\ From the Kuwait Medical Genetics Centre, Maternity Hospital, Kuwait.
}

SUMMARY A five year old boy is reported with hypoplastic, bowed tibiae and postaxial polysyndactyly. Sixteen relatives of both sexes in four generations either have bilateral syndactyly or postaxial polydactyly or both. The nature of the condition and the possible mode of inheritance are discussed.

Tibial hypoplasia associated with polydactyly has been described by several authors. ${ }^{1-5}$ All patients

Recived for publication 10 March 1986

Accepted for publication 16 April 1986. studied have had hypoplastic or absent tibiae, other craniofacial anomalies, and preaxial polydactyly. We report a case of a boy with a previously undescribed syndrome of hypoplastic tibiae with postaxial polysyndactyly.

\section{Case report}

The proband was a five year old boy delivered at term by lower caesarean section to first cousin Arab parents (father 37 and mother 33 years old). He had three older sibs (two males and one female). His birth weight was $3.8 \mathrm{~kg}$, length $48 \mathrm{~cm}$, and head circumference $36 \mathrm{~cm}$. He had bilateral postaxial polydactyly of both hands (surgically removed), clinodactyly of 
the fifth fingers, complete cutaneous syndactyly between the fourth and fifth fingers, postaxial polysyndactyly (fifth and sixth) of both feet, partial cutaneous syndactyly of the toes (second and third), and shortness of both legs with bowing (fig 1). He had no craniofacial abnormalities or other organ involvement.
Radiographic examination showed bowed, hypo $\stackrel{\overparen{D}}{\rightarrow}$ plastic tibiae and mild involvement of the fibulac: which appeared to be larger than the tibiae. No othef findings were detected in the skeletal survey (fig 2)

Pedigree study (fig 3 ) showed 16 affected person of both sexes in four generations. The elder sister $\vec{\sigma}_{\bar{\sigma}}$ the father, and seven paternal and maternaf
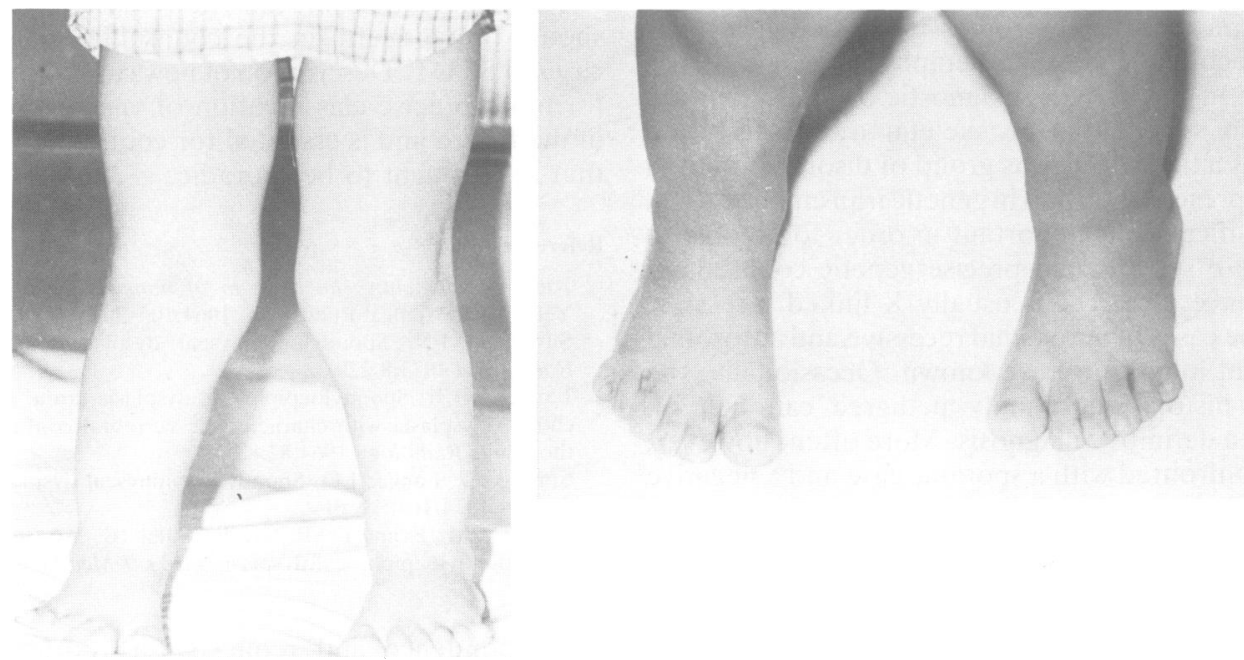

FIG 1 Legs and feet of the proband.
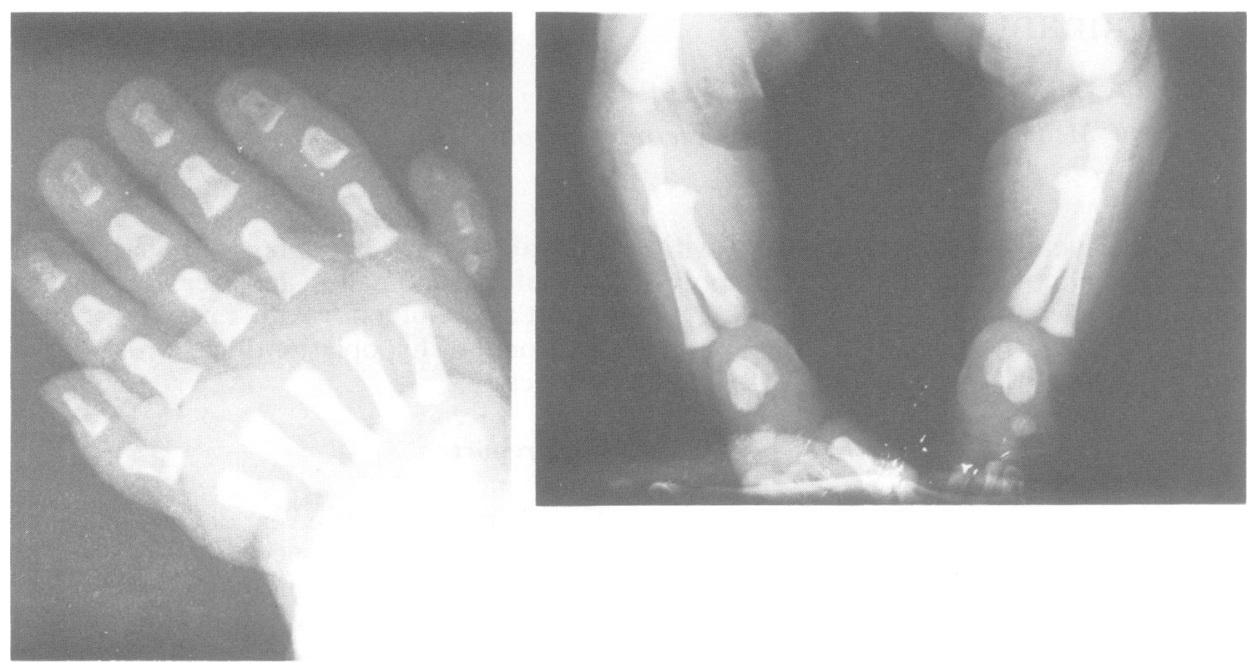

FIG $2 X$ rays of hand and legs of the proband. 


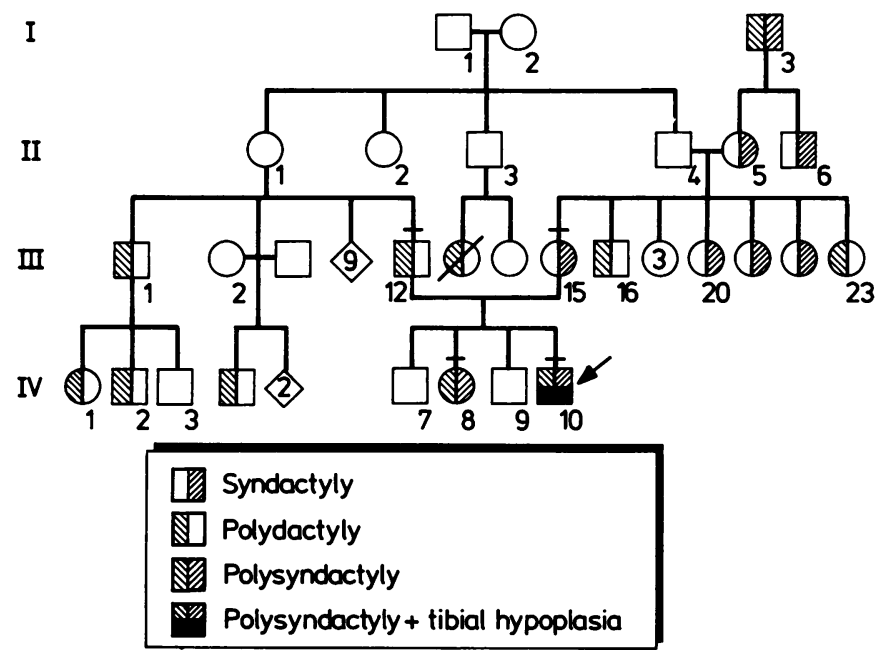

FIG 3 Family pedigree.

relatives had isolated postaxial polydactyly of type $A$ or $B$ and the mother and six maternal relatives had cutaneous syndactyly.

\section{Discussion}

Hypoplasia or absence of tibiae with polydactyly is a genetically heterogeneous developmental field defect. Cases with this limb defect and associated craniofacial anomalies have been reported. ${ }^{3}{ }^{7}$ All other reported cases without craniofacial anomalies had preaxial polydactyly. ${ }^{24589}$ It seems that the proband is a unique case of bilateral tibial hypoplasiapolydactyly without craniofacial anomalies.

The great grandfather of the proband (I.3) had polysyndactyly which was transmitted to 16 of his descendants in a family with frequent consanguineous marriages. There is a high inbreeding coefficient $(0 \cdot 02)$ in the area. ${ }^{10}$

From the pedigree study, it appears that there is a dominant gene responsible for the occurrence of polysyndactyly in both maternal and paternal family members, transmitted to the proband through his parents, but the proband also had tibial hypoplasia which was not present in any other family member including those with polysyndactyly. Although the explanation of this situation is not entirely plausible, two suggestions may be made. Either the tibial hypoplasia occurred coincidentally as a new mutation along with the inherited polysyndactyly, or the proband inherited two doses of the polysyndactyly gene from either of his parents, though the mother did not show any sign of polydactyly. Variability in expression and penetrance in polysyndactyly is illustrated in this family, where some members showed polydactyly type A (full finger), others showed polydactyly B (pedunculated postminimi), and others showed only syndactyly extending above the proximal interphalangeal joint. The suggestion of homozygosity in this case has been raised by $\mathrm{C} \mathrm{O}$ Carter (1980, personal communication) and $R$ Wynne Davies (1982, personal communication). As a result of this possible homozygosity, the clinical picture of the proband appeared more severe and was accompanied by other bone anomalies. Other dominant conditions have been reported in which homozygosity has been shown to produce a more serious defect than the heterozygous state. ${ }^{11} 12$

In conclusion, the proband has a new syndrome of bilateral tibial hypoplasia with postaxial polysyndactyly. No similar case has been reported so far. ${ }^{1314}$

\section{References}

1 Salzer M. Uber den kongenitalen defekt tibia. Zentralbl Chir 1960;17:673-7.

2 Eaton G, McKusick V. A seemingly unique polydactyly syndactyly syndrome in four persons in three generations. Limb malformations. Birth Defects 1969;V(3):221-5.

3 Sakati N, Nyhan W, Tisdale W. A new syndrome with acrocephalopolydactyly, cardiac disease and distinctive defects of the ear, skin and lower limbs. J Pediatr 1971;79:104-9.

4 Yujnovsky O, Ayalo D, Vincitoris A, Vialf H, Sakati N, Nyhan W. A syndrome of polydactyly, syndactyly and triphalangeal thumbs in three generations. Clin Genet 1974;6:51-9.

5 Canum S, Lomeli RM, Martinez R, Carnevale A. Absent tibiae, triphalangeal thumbs and polydactyly: description of a family and prenatal diagnosis. Clin Genet 1984;25:192-6. 
"Greig DM. Oxycephaly. Edinburgh Med J 1928:33:189-218.

7 Canki N. Syndactyly+polydactyly+triphalangeal thumbs with tibial hypoplasia and nose anomaly in two generations: a new syndrome 5th International Conference on Birth Defects, Montreal. 1977.

* Reber M. Un syndrome osseux peu common associate une heptadactylic et une aplasie des tibiae. J Genet Hum 1967;16: 15-39.

"Pashayan H, Fraser FC, McIntyre M. Dunbar J. Bilateral aplasia of the tibiae, polydactyly and absent thumb in father and daughter. J Bone Joint Surg (Br) 1971;53:495-9.

II' Al-Awadi SA, Moussa MA. Naguib KK, et al. Consanguinity among the Kuwaiti population. Clin Genet 1985;27:483-6.

1 Pauli R. Dominance and homozygosity in man. Am J Med Genet 1983;16:455-8.
12 Hirschhorn K. Dominance and homozygosity in man. Am J Me Genet 1984:18:534.

13 Temtamy S, McKusick V. Polydactyly. In: The genetics of han malformations. Birth Defects, vol XIV, No 3. New York: Th民 National Foundation-March of Dimes, 1978:364-439.

${ }^{14}$ McKusick VA. Mendelian inheritance in man. Catalog oक autosomal dominant, autosomal recessive and $X$-linked pheno types. 6th ed. Baltimore: Johns Hopkins University Press, 1983尺

Correspondence and requests for reprints to $D \vec{P}$ Kamal K Naguib, Kuwait Medical Genetics Centre $\vec{\rightleftarrows}$ Maternity Hospital, PO Box 4080, 13041 Safat Kuwait.

\section{Duplication $14(\mathrm{q} 31 \rightarrow \mathrm{qter})$}

DAISY M CARR, KWEI JONES-QUARTEY*,

MARGARITA V VARTANIAN, AND HELEN MOORE-KAPLAN

Cytogenetics Laboratory, Department of Pathology, Charles Drew/UCLA Medical School, Los Angeles, California 90059, USA.

SUMMARY A 29 year old black female with delayed development and multiple congenital anomalies showing a duplication of $14(\mathrm{q} 31 \rightarrow$ qter) is presented. Although clinical features associated with partial duplication of the distal long arm of chromosome 14 are variable, there are some features which are distinctive of this chromosomal abnormality. The clinical findings of 14 cases with duplication distal $14 \mathrm{q}$ are compared in an effort to define a recognisable syndrome.

Duplication of $14 \mathrm{p}$, the centromeric region, and various segments of proximal $14 \mathrm{q}$, has been observed in numerous patients with mental retardation and multiple congenital anomalies. Duplication of distal $14 \mathrm{q}$, however, has been observed in only a few cases. The present paper reports a case of duplication $14(\mathrm{q} 31 \rightarrow \mathrm{qter})$.

\section{Case report}

A 29 year old black female was referred to the KingDrew Medical Center from a nursing home because of vomiting and weight loss of five to six months' duration. Weight loss was ascribed to decreased food

*Present address: Department of Internal Medicine, Los Angeles County-USC Medical Center, Los Angeles. California 90033. USA.

Received for publication 22 April 1986. Accepted for publication 24 April 1986. intake. There were no other gastrointestinal symp toms. The patient had had a diagnosis of encephalo pathy due to unknown cause and defective fetap development with multiple congenital anomalies. Her IQ from a previous evaluation was at an 11 year old level. She had been born prematurely at $71 / 2$ months? gestation, the third child of a mother described as being anaemic and having unspecified cardiacō problems. The patient had a history of frequen? upper respiratory infections and bilateral pneumonia? She had had extensive dental surgery for multiple caries and periodontitis.

Upon admission, the patient was afebrile with a blood pressure of $100 / 70$. She was poorly nourisheds and underdeveloped with proportionately smalkु

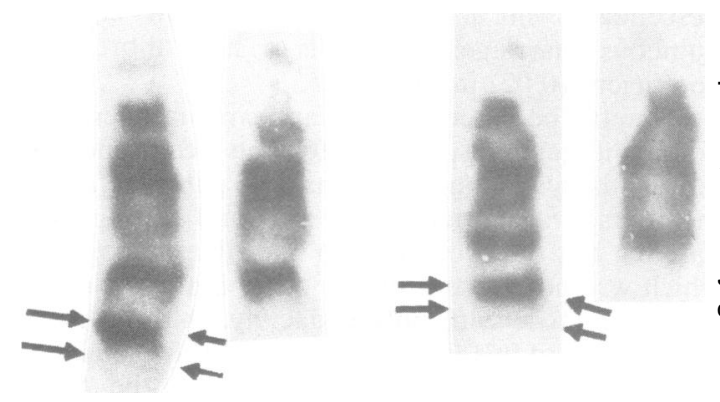

FIGURE Chromosome 14 pairs from the proband showing duplication of 14 (q31 $\rightarrow$ qter $)$. 